\title{
AWARENESS REGARDING VESICOVAGINAL FISTULA AMONG WOMEN RESIDING IN A MUNICIPALITY OF KAPILVASTU
}

Saraj Gurung, ${ }^{1}$ Vidya Panthi, ${ }^{2}$ Anuja Kachapati ${ }^{1}$

\section{ABSTRACT}

\section{INTRODUCTION}

Vesicovaginal fistula (VVF) is one of the most distressing maternal morbidities. It is a physically and socially disabling obstetric complication that affects many women annually. It has a devastating social, economic and psychological effect on the health and well-being of the affected women. The aim of the study was to find out awareness regarding vesicovaginal fistula among women.

\section{MATERIAL AND METHODS}

Descriptive study design was used for the study to find out awareness regarding vesicovaginal fistula. Hundred women were selected as the study sample by non purposive and snow ball sampling technique. Pretested semi structured interview schedule was used for data collection and analyzed by using descriptive and inferential statistics.

\section{RESULTS}

The findings of the study revealed that $81 \%$ and $100 \%$ of women knew that delivery by non skilled and wetting under garments is risk factor and symptom of VVF. $82 \%$ and $73 \%$ of women knew that VVF is preventable and curable respectively. $58 \%$ of women had knowledge that women can become pregnant in case of VVF and $47 \%$ knew that VVF can be reoccurred. Out of 73 women, $23 \%$ knew that surgery as the treatment of VVF. Forty nine percentage of women had answered regarding family and social misbehave and depression (5\%) being social consequences of VVF. Seventy percentage of women answered that cervicitis is complication of VVF.

\section{CONCLUSION}

Based on the findings of the study half of the women had low knowledge regarding VVF. So, it is recommended to organize continue awareness program to the women regarding VVF.

KEYWORDS Awareness, vesicovaginal fistula, community

1. Universal College of Nursing Sciences, Bhairahawa, Nepal

2. Gautam Buddha Community Heart Hospital, Butwal, Nepal

DOI: https://doi.org/10.3126/jucms.v6i2.22495

For Correspondence

Ms. Saraj Gurung

Universal College of Nursing Sciences

Bhairahawa, Nepal

EMail:g.saraj@gmail.com 


\section{INTRODUCTION}

Vesicovaginal fistula (VVF) is a subtype of female urogenital fistula (UGF). VVF is an abnormal fistulous tract extending between the bladder and the vagina that allows the continuous involuntary discharge of urine into the vaginal vault. ${ }^{1}$ Global burden of study suggested that obstructed labour affects at least 7 million women every year, 6.5 million of whom live in the least-developed regions of the world. Only $2 \%$ of obstructed labour in the developing world result in a subsequent fistula, 130000 new cases would be added each year. ${ }^{1}$ VVF is usually caused by child birth called as an obstetric fistula, when a prolonged labor presses the unborn child tightly against the pelvis, cutting off blood flow to the vesicovaginal wall. The affected tissue may necrotize leaving a hole. If obstructed labour is not treated by caesarean section, it can result in death of baby and the mother or fistula for mother who survives. VVF can also result from violent rape; this injury has become common in some war zones, where rape is used as a weapon against civilian populations resulting to $\mathrm{VVF}^{2}$

VVF following hysterectomy is most likely to arise from an unrecognized bladder injury at the time of surgery which results in the formation of an urinoma. A second possible mechanism is pressure necrosis from incorrectly placed sutures between the vaginal cuff and posterior bladder. Hematoma and infection are often complicating factors. ${ }^{3}$ Women with fistula mention offensive order as a source of shame, stigma and isolation. The majority of women who sustain an obstetric fistula are abandoned by their husband and many shunned by their families. All these could lead to low self esteem which impact on receptiveness to preventive measures. ${ }^{4}$ Unfortunately, some women get recurrence of VVF, either from poor healing or during subsequent pregnancies. The chances of success of VVF repair during second or third attempts are very low. ${ }^{5}$

\section{MATERIAL AND METHODS}

Descriptive study design was used to find out awareness regarding VVF among women. The study was conducted in Buddhabhumi municipality ward no. 24, Kapilvastu. Hundred women were selected as sample by non probability purposive and snow ball sampling technique. Interview method was used for data collection with use of pretested semi structured questionnaire developed by researchers by reviewing the related literatures consulting with the subject experts. There were 20 questions regarding VVF. Data collection was done in April to September, 2017. Administrative and ethical approval was obtained from concerned authorities prior to data collection.
The researchers contacted each respondent (married woman aged 20-49 years having at least one child) and obtained written informed consent for the study and interviewed. Researchers interviewed five to six respondents per day and only one woman was included in the study from one household. Descriptive and inferential statistical method was used with SPSS Version 16.

\section{RESULTS}

Regarding socio-demographic variables, mean age of the respondents was 37.75 years. About sixty percent respondents were Brahmin/Chhetri and $63 \%$ of respondents were homemaker. Ninety-nine percentage of the respondents were literate and $100 \%$ had no positive family history of VVF. Among 137 respondents, 100 (72.99\%) of respondents had heard about VVF.

Respondents' awareness regarding risk factors of VVF, 81\% of respondents answered delivery by non skilled and $16 \%$ answered hysterectomy. Mean percentage score of awareness regarding risk factors of VVF is 55.

Table 1. Respondents' awareness regarding risk factors of VVF $\mathrm{n}=\mathbf{1 0 0}$

\begin{tabular}{lll}
\hline Risk Factors of VVF & \multicolumn{2}{c}{ Correct response } \\
\hline & Frequency & Percentage \\
\hline Prolonged obstructed labour & 68 & 68.0 \\
Delivery by non skilled worker & 81 & 81.0 \\
Home delivery & 40 & 40.0 \\
Hysterectomy & 16 & 16.0 \\
Sexual violence & 70 & 70.0 \\
\hline
\end{tabular}

Mean percentage score $=55.0$

As regards symptoms of VVF, $100 \%$ of respondents answered wetting of under garments and of $50 \%$ of respondents answered vulval pruritus. Mean percentage score of symptoms of VVF is 84.6.

Table 2. Respondents' awareness regarding symptoms of VVF $\mathrm{n}=\mathbf{1 0 0}$

\begin{tabular}{|c|c|c|}
\hline \multirow[t]{2}{*}{ Symptoms of VVF } & \multicolumn{2}{|c|}{ Correct response } \\
\hline & Frequency & Percentage \\
\hline Urinary incontinence & 97 & 97.0 \\
\hline No urge to pass urine & 83 & 83.0 \\
\hline Vulval pruritus & 50 & 50.0 \\
\hline Foul smelling & 93 & 93.0 \\
\hline Wetting of under garments & 100 & 100.0 \\
\hline
\end{tabular}

Mean percentage score $=84.6$

Regarding general concepts of VVF, $82 \%$ of the respondents answered VVF is preventable, curable (73\%), not hereditary 
$(70 \%)$ and not communicable (60\%). Fifty eight percent of respondents answered that it is possible to have pregnancy with VVF and $47 \%$ answered it reoccurs.

\begin{tabular}{lll} 
Table 3. Respondents' awareness regarding VVF & $\mathbf{n = 1 0 0}$ \\
\hline Facts about VVF & \multicolumn{2}{c}{ Correct Response } \\
\cline { 2 - 3 } & Frequency & Percentage \\
\hline VVF is not communicable & 60 & 60.0 \\
VVF is not hereditary & 70 & 70.0 \\
VVF is preventable & 82 & 82.0 \\
VVF is curable & 73 & 73.0 \\
VVF is reoccur & 47 & 47.0 \\
Women with VVF can become & 58 & 58.0 \\
pregnant & & \\
\hline
\end{tabular}

Mean percentage score $=65$

Out of 82 respondents who answered VVF is preventable, $50 \%, 64.63 \%$ and $87.80 \%$ of respondents answered delaying marriage, delivery by skilled birth attendance and regular antenatal checkup respectively are preventive measures of VVF.

Table 4. Respondents' awareness regarding prevention of VVF

$\mathrm{n}=\mathbf{8 2}$

\begin{tabular}{lll}
\hline Prevention of WF & \multicolumn{2}{l}{ Correct Response } \\
\cline { 2 - 3 } & Frequency & Percentage \\
Delaying marriage & 41 & 50.0 \\
Regular antenatal check up & 53 & 64.63 \\
Delivery by skilled birth attendance & 72 & 87.80 \\
\hline
\end{tabular}

Mean percentage score $=67.47$

Regarding social consequence of VVF, $49 \%$ of respondents answered family and social misbehave (hates) are consequences of VVF and $5 \%$ of respondents answered depression.

Table 5. Respondents' awareness regarding social consequences of VVF

\begin{tabular}{lll} 
& & $\mathbf{n = 1 0 0}$ \\
\hline Consequences of VVF & Frequency & Percentage \\
\hline Social isolation & 10 & 10.0 \\
Depression & 5 & 5.0 \\
Physical violence & 7 & 7.0 \\
Second marriage & 16 & 16.0 \\
Kick out from home & 13 & 13.0 \\
Family and social misbehave & 49 & 49.0 \\
\hline
\end{tabular}

Mean percentage score $=16.66$

As regards complication of VVF, 70\% of respondents answered cervicitis and $38 \%$ of respondents answered recurrent fistula formation is a complication of VVF.
Table 6. Respondents' awareness regarding complications of VVF

\begin{tabular}{lll}
\hline Complications of VVF** & Frequency & Percentage \\
\hline Recurrent fistula formation* & 38 & 38.0 \\
Cervicitis & 70 & 70.0 \\
Irritative lower urinary tract* & 50 & 50.0 \\
Reduced bladder capacity* & 58 & 58.0 \\
Salpingitis & - & - \\
\hline
\end{tabular}

**Multiple responses $\quad *$ Correct response

*Mean percentage score $=48.66$

Regarding overall awareness regarding VVF, $50 \%$ of respondents had high awareness of VVF. Total score was 19 and mean score was 12.29 .

Table 7. Respondents' overall awareness regarding VVF

\begin{tabular}{lll} 
& & $\mathbf{n = 1 0 0}$ \\
\hline Awareness level & Frequency & Percentage \\
\hline High & 50 & 50.0 \\
Average & - & - \\
Low & 50 & 50.0 \\
\hline
\end{tabular}

Mean score $=12.29$

\section{DISCUSSION}

The study was conducted to find out the awareness regarding vesico vaginal fistula among women residing in a municipality of Kapilvastu.

The findings of the study showed that out of 137 respondents, $72.99 \%$ of respondents had heard about VVF which is not consistent with the study ${ }^{6}$ conducted in Burkina Faso which shows that $36.4 \%$ of respondents had heard about VVF.

The findings of the study showed that $68 \%$ of respondents knew prolonged obstructed labour is risk factor of VVF which is not consistent with the study ${ }^{7}$ conducted in Sub-Saharan Africa which shows that $36.3 \%$ of respondents knew that prolonged obstructed labour is risk factor of VVF.

The findings of the study showed that $82 \%$ of respondents knew that delivery by non skilled worker increases the risk factor of VVF which is not consistent with the study ${ }^{8}$ conducted in Afghanistan which shows that 23.2\% of respondents were aware that delivery by non skilled worker is risk factor of VVF.

The findings of the study showed that $40 \%$ of respondents knew that home delivery is the risk factor of VVF which is consistent with the study ${ }^{6}$ which shows that $38 \%$ of respondents knew that home delivery is risk factor of VVF. 
The findings of the study showed that, $16 \%$ of respondents knew that hysterectomy is risk factor of VVF which is not consistent with the study ${ }^{7}$ which shows that $71.1 \%$ of respondents were aware that hysterectomy is the risk factor of VVF.

The findings of the study showed that $70 \%$ of respondents had knowledge that sexual violence is risk factor of VVF which is not consistent with the study ${ }^{7}$ which shows that $23 \%$ of respondents had knowledge that sexual violence is risk factor of VVF.

The findings of the study showed that $97 \%$ of respondents knew that urinary incontinence is symptom of VVF which is not consistent with the study ${ }^{6}$ which shows that $90 \%$ of respondents knew that urinary incontinence is symptom of VVF.

The findings of the study showed that $100 \%$ of respondents had knowledge that wetting of under garments is a symptom of VVF which is not consistent with the study ${ }^{7}$ which shows that $72 \%$ of respondents knew that wetting of under garments is a symptom of VVF.

The findings of the study showed that $50 \%$ of respondents stated that vulval pruritus is a symptom of VVF which is not consistent with the study ${ }^{6}$ conducted in Burkina Faso which showed that $72 \%$ of respondents said that vulval pruritus is symptom of VVF.

The findings of the study showed that $83 \%$ and $93 \%$ of respondents knew that no urge to pass urine and foul smelling is a symptom of VVF respectively.

The findings of the study showed that $73 \%$ of respondents said that VVF is curable among them $23 \%$ knew operation is the treatment of VVF. Forty seven percent of respondents knew that VVF reoccurs, not communicable $(60 \%)$ and not hereditary $(70 \%)$

The findings of the study showed that $82 \%$ of women had knowledge that VVF is preventable. Among them $87.80 \%$ of respondents said that delivery by skilled birth attendant is preventive measure of VVF which is not consistent with the study ${ }^{9}$ which shows that $76 \%$ of respondents knew that delivery by skilled birth attendant is preventive measure of VVF.

The findings of the study showed that $16 \%$ and $5 \%$ of respo ndents had knowledge that second marriage and depression is social consequence of VVF which is not consistent with the study ${ }^{10}$ which shows that $54.7 \%$ and $54 \%$ of respondents knew that second marriage and depression is social consequence of VVF respectively.
The findings of the study showed that $20.6 \%$ and $29.4 \%$ of respondents knew that recurrent fistula formation and reduced bladder capacity is complication of VVF which is not consistent with the study ${ }^{11}$ which shows that $42 \%$ and $58 \%$ of respondents knew that recurrent fistula formation and reduced bladder capacity is a complication of VVF respectively.

The findings of the study showed that $6.9 \%, 8.3 \%, 13.9 \%$ and $51.4 \%$ of respondents were aware that social isolation, physical violence, kick out from home and family and social misbehave (hates) is consequence of VVF respectively. The finding of the study shows that $17.5 \%$ of respondents expressed that irrigative lower urinary tract is complication of VVF respectively.

There was statically no significant association between level of awareness regarding VVF and age group of respondents $(\mathrm{p}=0.354)$.

\section{CONCLUSION}

On the basis of findings of the study, it is concluded that overall half of the women have high knowledge regarding VVF. Majority of women know regarding risk factors, symptoms and prevention of VVF. Women have less knowledge regarding social consequences and complications of VVF.

\section{ACKNOWLEDGEMENTS}

Researchers deeply express their heartfelt thanks to all women who participated in the study for immense support and cooperation. Researchers express their deep and sincere gratitude to all those experts for their valuable judgment, constructive feedbacks and enlightening suggestions throughout the study.

\section{REFERENCES}

1. Spurlock, J. Vesico vaginal fistula: Background, History of the procedure, problem 2016. Retrived from: emedicine. medscape. com.

2. Ngoma, J. Prevention of vesico vaginal fistula, Turku University of Applied Sciences, (Bachelor Thesis), 2010.

3. Garthwaite M, Harris N. Vesicovaginal fistulae. Indian journal of urology: IJU: journal of the Urological Society of India. 2010 Apr;26(2):253-256.

4. Roush KM. Social implications of obstetric fistula: an integrative review. The Journal of Midwifery \& Women's Health. 2009 Mar 4; 54(2):e21-33.

5. Holme A, Breen M, MacArthur C. Obstetric fistulae: a study of women managed at the Monze Mission Hospital, Zambia. BJOG: 
An International Journal of Obstetrics \& Gynaecology. 2007 Aug 1;114(8):1010-1017.

6. Banke-Thomas AO, Kouraogo SF, Siribie A, Taddese HB, Mueller JE. Knowledge of obstetric fistula prevention amongst young women in urban and rural Burkina Faso: a cross-sectional study. PloS one. 2013 Dec 31;8(12):e85921.

7. Maheu-Giroux M, Filippi V, Maulet N, Samadoulougou S, Castro MC, Meda N, Pouliot M, Kirakoya-Samadoulougou F. Risk factors for vaginal fistula symptoms in Sub-Saharan Africa: a pooled analysis of national household survey data. BMC pregnancy and childbirth. 2016 Dec;16(1):82.

8. Mohmand K. A, Sharifi K, Bahram A. Survey report: prevalence of obstetric fistula among women of reproductive age in six provinces of Afghanistan, 2011(Doctoral Dissertation).

9. Walz NK, Faroqul M, Begum A, Sultana N, Sarker S, Faisel AJ. Situation analysis of obstetric fistula in Bangladesh. Dhaka, Engender Health. 2003 Sep.

10. Kimani ZM, Ogutu O, Kibe A. The prevalence and impact of obstetric fistula on women of Kaptembwa-Nakuru, Kenya. International Journal of Applied. 2014 May;4(3):273-87.

11. Kasamba N, Kaye DK, Mbalinda SN. Community awareness about risk factors, presentation and prevention and obstetric fistula in Nabitovu village, Iganga district, Uganda. BMC pregnancy and childbirth. 2013 Dec;13(1):229. 